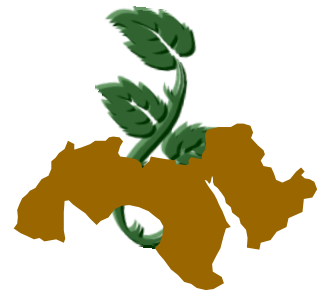

\title{
PRELIMINARY STUDIES USING GIS AND FIELD SURVEY TO DETERMINE LAND COVER IN EGYPT
}

\author{
Abou-Hadid', A.F.; M.A. Medany'; M. Abdrabbo'; M.K. Hassanein'; A.A. Farag'; \\ S.M. Abolmaaty'; A.A. Khalil'; K.M. Refaie ${ }^{1}$; S.M. Saleh ${ }^{1}$; F.A. Hashem ${ }^{1}$; \\ A.A. Ismael' ${ }^{1}$ M. Saied ${ }^{1}$; A. Kadah ${ }^{1}$; T. Kadah ${ }^{1}$; M. Kadah ${ }^{1}$; A.T. El-Morsi' \\ M. Bertin ${ }^{2}$; G. Jaffrain ${ }^{2}$ and A. Elgueroua ${ }^{2}$ \\ 1- The Central laboratory for Agricultural Climate, Agricultural Research Centre, Dokki, Giza, \\ Egypt \\ 2- French National Geographic Institutes (IGN). PARIS- France
}

Keywords: Satellite image, Topographic maps, Nile Delta and Valley, Remote sensing and Global Positioning System (GPS)

\begin{abstract}
In the present study a suitable methodology is developed for estimating crop area by integrating remote sensing and GIS based on land survey approach. Area frame surveys are common approaches to gather land cover data. In contrast to mapping approaches, area frame sampling is a statistical method. Based on the visual observation of sample geo-referenced points, area estimates are computed and used as a valid generalization without studying the entire area under investigation. The approach has also the important advantage of not involving/disturbing the land owners and the farmers. The survey concerning the estimation of yield for the major crop will be carried out by cutting small samples in the field. The sample covers the whole Nile valley and the delta, the observed area is about $35000 \mathrm{~km}^{2}$ and the distance from South to North is about $1000 \mathrm{~km}$. Digital topographic maps $1: 5000$ and SPOT5 satellite Images was used, 2,5m resolution, Ortho-rectified (DTM). The survey used the WGS84, Universal Transverse Mercator $36 \mathrm{~N}$, which parameter are given hereafter. Three thousands sites were visited during the winter crop survey, the sample could be constituted of a sub-set of these sites and one point will be designed in each of the selected sites. If this point is wheat, it will be included in the yield sample and visited at harvest time. The sub sam-
\end{abstract}

ple is defined as points of observation, $250 \mathrm{~m} x$ $250 \mathrm{~m}$ apart; there are 10 points of observation, which are called points. They are located in two lines East-West of 5 points. There suits of winter survey of Nile Delta and Nile valley is about 12591563 Feddan. The main results of the field survey were that the total cultivation area is almost 76609500 Feddan. The cultivation area is covered about $61 \%$ of the total Nile Delta and Nile valley. Field crop is the major area in the Nile valley and Nile Delta, its cover about $48 \%$ of the total area of the Nile Valley and Nile Delta. Furthermore, the field crops cover about $79 \%$ of the total cultivation area.

\section{INTRODUCTION}

Monitoring, estimating and forecasting agricultural production are very important for the management of world / regional or local food demand and supply balance for social security. Attempts have been made in improving agricultural statistics using area frame sampling techniques with the consideration that classical methods of generating of agricultural statistics are time consuming, costly and subject to a variety of errors (Pradhan, 2001). Due to the enormous problems related to crop identification using remote sensing imagery many researchers have attempted to estimate crop area using an integration of sampling techniques and satellite sensor images (Loveland et al 2002). The method is that regression estimators are used to combine ground data with satellite sensor images. Confusion matrices obtained by evaluating the 
performance of the supervised classification are used to generate a matrix of conditional probabilities. The conditional probability is the probability of obtaining a reference class as a result of the supervised classification (Gonzalez-Alonso and Cuevas, 1993).

In many developing countries like Ghana, agricultural statistics disseminated in incompatible formats (tabular and graphs) that lack Georeferencing as second level administrative aggregates. Yet administrative areas are arbitrary in geographical terms varying in size, shape and time posing serious problems for attempts to map or interpret spatial patterns in statistical data or integrate such data with other data sets (Rogana and Chen, 2004). In addition to this, analyses based on such synoptic data make extrapolations to lower administrative levels difficult (Rasmussen, 1997). Remote sensing plays an important role as auxiliary variable in the production of agricultural statistics, when area frame or multiple frames sample designs are used. It can be used at the design level as well as at the estimator level. At the design level, the most typical use of remote sensing data is in the area frame construction and stratification. Remote sensing data can also be used to optimize the sample design where a previous ground survey is not performed; in fact, spatial characteristics (e.g. correlograms) of variables of interest can be estimated on the basis of photo interpretation of remote sensing images (Quarmby et al 1993).

Another important way of getting estimates with better precision and the same sample size is taking into account the positive spatial autocorrelation of agricultural variables, for example through the DUST (Dependent area Units Sequential Technique). This sampling technique (Ali et al 2007) modifies the simple random sampling selection probabilities once a first set of segments has been sampled to estimate the area covered by a crop in a region. In fact, the estimator based on the ratio between the number of pixels classified into the specific crop and the total number of classified pixels is known to be strongly biased. Similar problems arise when photo-interpretation of satellite images is used for crop area estimation, since photo-interpretation errors tend to be systematic and, generally, there is no compensation between commission and omission errors for the different crops (Ayala-Silva et al 2009).

The objectives of this work is to have general view about land cover during 2008-2009 cultivation season.

\section{MATERIALS AND METHODS}

The studies area was the Nile Delta and Nile Valley as shown in Figure (1). Data on land cover and environmental features are collected in the field in the spring time at around 30.000 observation points in Nile Valley and Nile Delta surveyed by using Global Positioning System (GPS) devices (Lenney et al 1996).

\section{Determine area or point sampling}

The decision to sub sample the segment area through a grid of points is straight forward when looking to the structure of variance (variance between segments and variance between points within segments). In all our sampling simulation, the component of variance related to the second stage rarely reached $5 \%$ of the total variance Figure (2).

For the above reasons, the sampling plan adopted consists of one systematic square grid2 $(1 \times 1.5 \mathrm{Km})$ and rectangular segments of $2 \times 5$ points $250 \mathrm{~m}$ apart. This imposes due to the absence of replicates-an approximate estimation of variance through the differences between neighboring sampling units.

Area frame surveys are common approaches to gather land cover data. In contrast to mapping approaches, area frame sampling is a statistical method. Based on the visual observation of sample geo-referenced points, area estimates are computed and used as a valid generalization without studying the entire area under investigation. The survey was started at January, 15, 2009. The sample covers the whole Nile valley and the delta, the observed area is about $35000 \mathrm{~km}^{2}$ and the distance from South to North is about $1000 \mathrm{~km}$ Figure (1) One hundred surveyors, each of the hundred of surveyors will visit a 1/100 of this area, and a set of supervisors is necessary to manage this network of surveyors. A supervisor will cover a regional zone and should manage about ten or twelve surveyors (Jensen and Cowen, 1999).

\section{Determine field survey sites}

The sampling plan is systematic and has two levels Figure (2): Primary Sampling Unit (PSU) and Secondary Sampling Unit (SSU).

The primary sampling Unit is based on a regular grid $1 \times 1,5 \mathrm{~km}$ coming from the Egyptian cadastral maps $1 \times 1,5 \mathrm{~km}$. The cadastral maps were elaborated by the Egyptian Survey Authority 

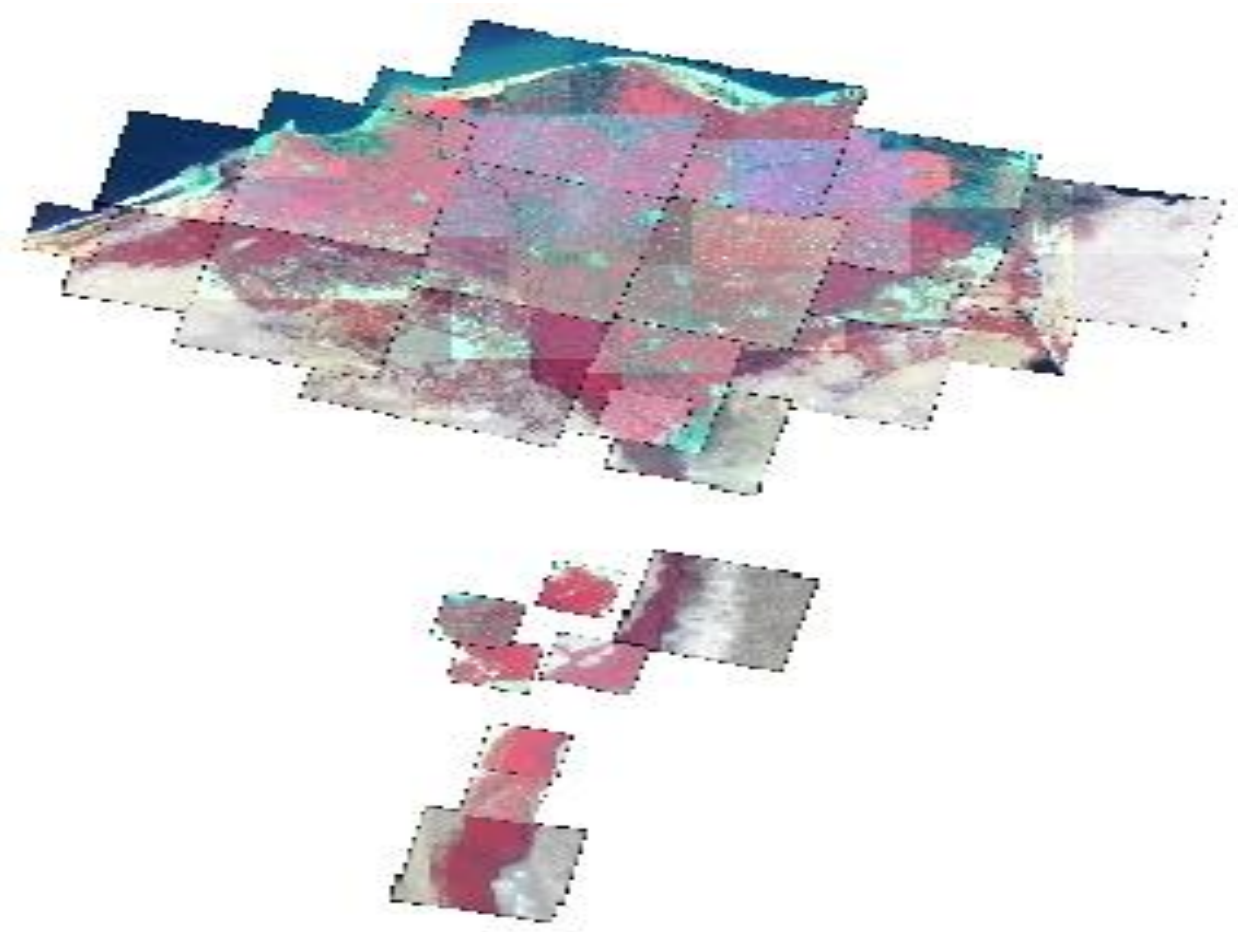

Red color: mean high chlorophyll activities such as crops

Light blue: Urban

Light grey: Bare soil
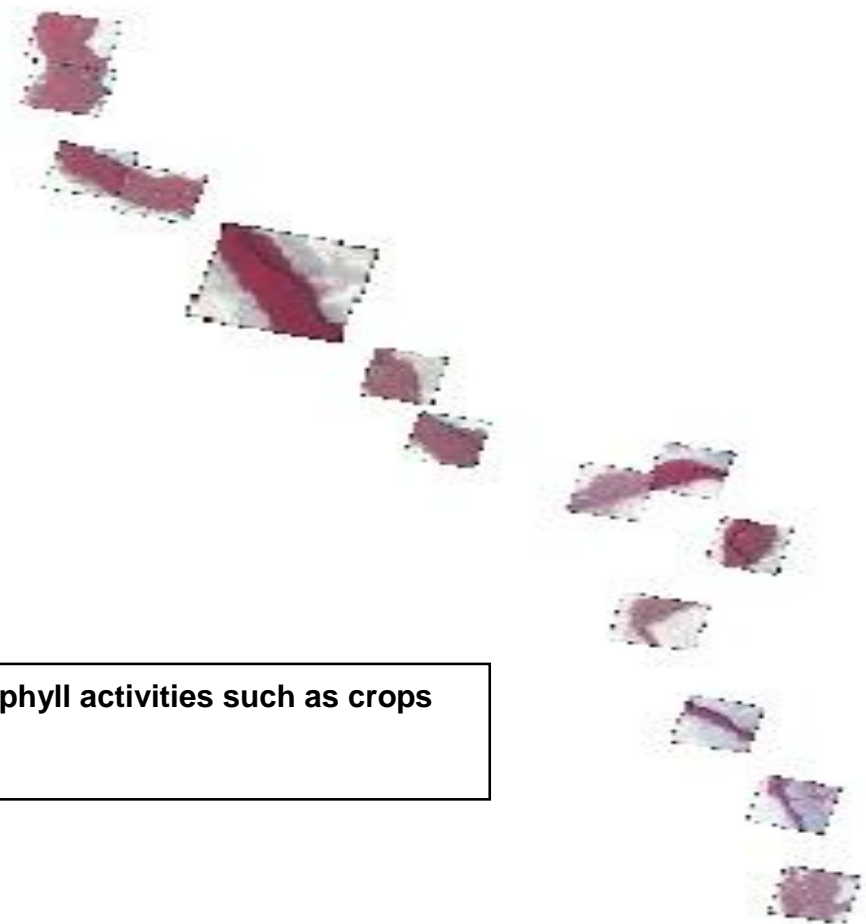

Figure 1. Satellite image covered the Nile delta and Nile valley 


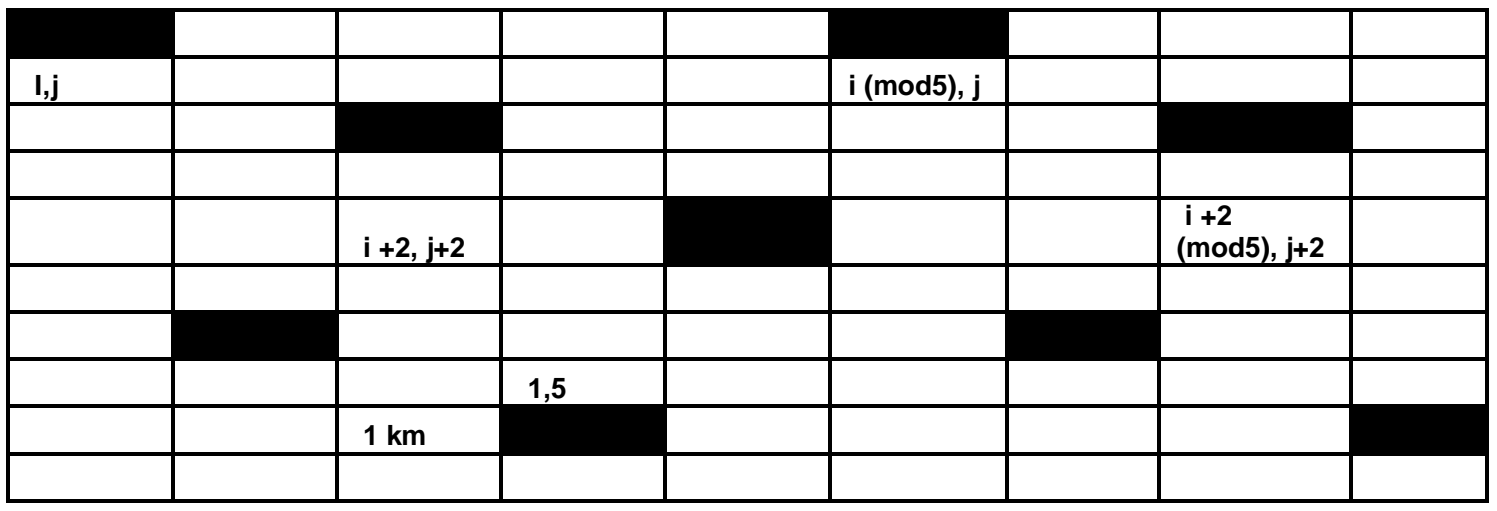

Determine of sub site (Points)

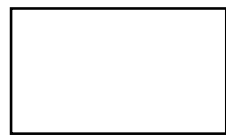

Initial grid $1 \times 1,5 \mathrm{~km}$ sq in Transverse Mercator, Red Belt projection

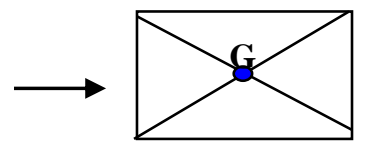

Definition of the centroïd "G" coordinate $(X, Y)$ in Transverse mercator Red

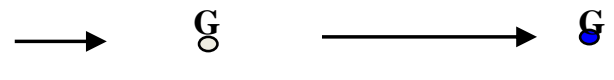

Projection transformation in UTM 36N WGS84 New Coordinate $(X, Y)$
Round off the Coordinate $(X, Y)$

$X=A A A A 00$ or $X=A A A A 50$

$Y=B B B B 00$ or $Y=$ BBBB50

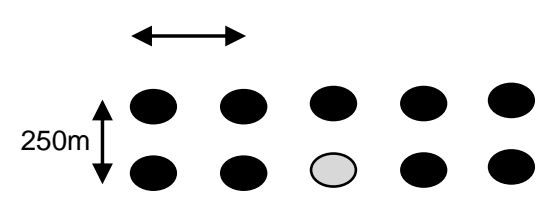

Final selection of 10 point Creation a new grid of point under Arc Info software

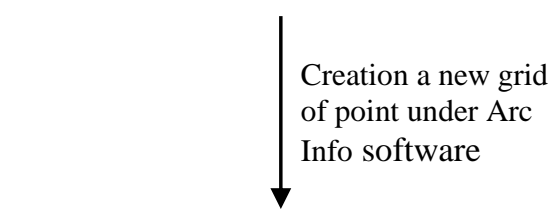

Numbering of point according to the line and column

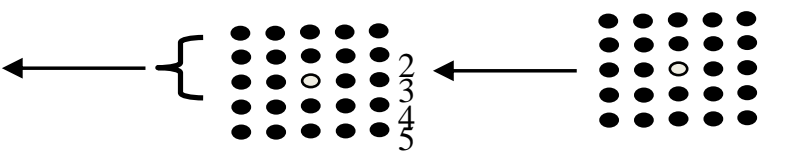

Grid of 25 points $250 \mathrm{~m} \times$ $250 \mathrm{~m}$ apart. The full coordinate for each point are round off

Figure 2. Methodology of selection the sub - sites

(ESA). They have been then updated by the Ministry of Agriculture using aerial photographs in the year 1985. The PSU represents an area of around $1,5 \mathrm{~km}^{2}$ (Rembold et al 2000). The index grid of the maps has been drawn over the full Egyptian territory. The systematic random has been carried out in chosen then one out of ten sheets according to the following algorithm. Sx,y = ith (modulo 5) column on the jth row, and $(i+2)$ th $(\bmod 5)$ column on the $(j+2)$ th row (Lambin and Elrlich, 1997).

The following examples show the georeferenced Grid $1 \times 1,5 \mathrm{~km}$ covering the entire Delta and Nile Valley including around a buffer zone in order to take into account a potential agriculture extension over the desert. The coordinate system used for all geographic data were download on GPS devices to every surveyor (100 surveyor covered all Nile delta and Nile valley. National grid Egyptian Transverse Mercator (Red Belt). The survey used the WGS84, Universal Transverse Mercator $36 \mathrm{~N}$, which parameter are given hereafter (Ayala-Silva et al 2009).

The SSU's are defined as points of observation, $250 \mathrm{~m} \times 250 \mathrm{~m}$ apart; there are 10 points of observation, which are called points. They are located in two lines East-West of 5 points. 
From the previous grid of selected site coming from the previous project some steps was implemented in order to obtain the final grid of 10 point used for CIPA project. The different steps are described below:

\section{Nomenclature}

The design of the nomenclature is based on "Classification system for land cover" (Eurostat 2000). Various existing national and international classification systems have been analysed to establish best practice for the construction of a classification system to be used in the framework of LUCAS (Youssef et al 2009).

The main points which were the object of analysis and choices were:

- The definition of Land (extended to inland water), of Land Cover (above the earth's surface).

- The observation unit: a circle of $3 \mathrm{~m}$ of diameter except in case of heterogeneous areas or permanent crops,

- The separate registration of multiple use/cover in order to avoid mixed classes,

- The treatment of points on limits and the use of ortho photography,

- The documentation of the classes in terms of definition, list of inclusions and exclusions, compatibility between land cover,

- The correspondence with existing national or international classification systems.

\section{Estimators}

Three main types of estimators will be used in function of the variable of interest was the area estimates: point sampling has the characteristic of having a sampling probability proportional to the size of the selected unit. For area estimates of land cover classes, this has the major interest that an unbiased estimate is obtained by multiplication of the area of interest by the percentage of points falling in the category of interest.

\section{Preliminary survey Results}

The results of winter field survey based on using the satellite images, topographic map and using GPS devices at January, 2009 is show in Figure (3) and Table (1). The total area of Nile Delta and Nile valley is about 12591563 Feddan. The total cultivation area is almost 76609500 feddan. The cultivation area is covered about $61 \%$ of the total Nile Delta and Nile valley.

Field crop land cover is the major area in the Nile valley and Nile Delta, its cover about $48 \%$ (6056,284 Feddan) of the total area. Furthermore, the field crops cover about $79 \%$ of the total cultivation area, the wheat and berseem is covered about $75 \%$ of the total field crop area Figure (3) and the other field crops (onion, garlic,.....etc) is covered about $25 \%$ of the total field crops area. The desert was come in the second land cover option, its cover about $11 \%$ (1433971 Feddan) of the total land cover area of Nile delta and Nile Valley, some of the desert location start to reclaim during the last two years. The urban (Town and villages) was covered about $7.0 \%$ of the total Nile delta and Nile valley areas. Potato area covered about $20.61 \%$ of the total vegetable area Figure (4) and Table (2). Fruit trees covered about 9\% (1146624 Feddan) of the total studied area.

\section{Conclusion}

The land cover changes in the Eastern Nile Delta of Egypt could be summarized as; a) the urban settlements increased considerably with high rate of annual increase every year; b) slight increase in the total cultivated area while the annual rate of agricultural reclamation decreased significantly in the last few years; c) the rate of change for desert areas is stable. There is an urgent need to activate the agricultural reclamation effort to run in parallel with the urbanization processes in this area. Future work with more satellite images and ground truth data may help to map the land cover changes with maximum level of accuracy. The Nile Delta and Nile Valley survey has already been a long process, started in September 2008. 


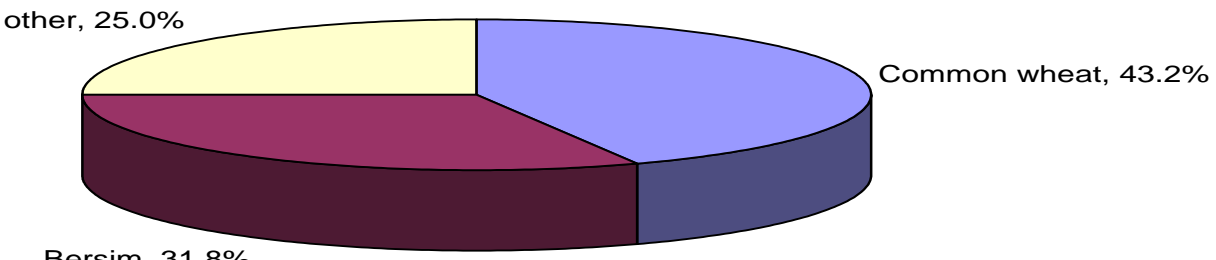

Bersim, 31.8\%

Figure 3. Percentage of main crops in the Nile Delta and Nile valley during 2008/09 winter survey

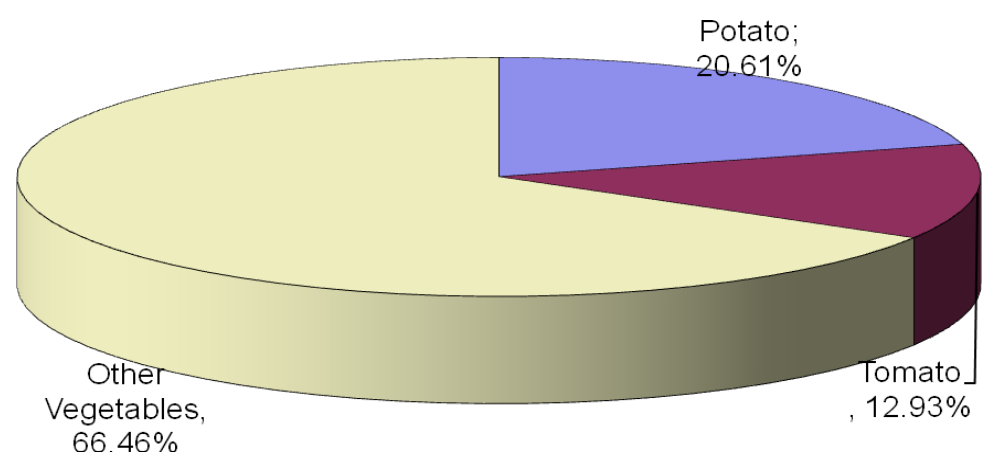

Figure 4. Percentage of main vegetables in the Nile Delta and Nile valley during 2008/09 winter survey

Table 1. Preliminary survey results of Nile Delta and Nile valley during 2008/09 winter survey for major items

\begin{tabular}{|l|c|c|}
\hline \multicolumn{3}{|c|}{ Area } \\
\hline \multicolumn{1}{|c|}{ Item } & $\begin{array}{c}\text { Area } \\
\text { (Feddan) }\end{array}$ & Percentages \\
\hline Towns, villages & 989196 & $7.86 \%$ \\
Greenhouses & 64010 & $0.51 \%$ \\
Roads, tracks & 558576 & $4.44 \%$ \\
Canals, ditches & 398691 & $3.17 \%$ \\
Cropland & 6056,284 & $48.10 \%$ \\
permanent crops & 1146624 & $9.11 \%$ \\
Agricultural bare land & 461722 & $3.67 \%$ \\
Woodland & 31084 & $0.25 \%$ \\
Shrubland, steppe & 134571 & $1.07 \%$ \\
Grassland & 112021 & $0.89 \%$ \\
Desert & 1433971 & $11.39 \%$ \\
Other bare land & 359264 & $2.85 \%$ \\
Wetland & 80412 & $0.64 \%$ \\
Lakes, water ponds & 308013 & $2.45 \%$ \\
Nile river & 47377 & $0.38 \%$ \\
Sea & 69537 & $0.55 \%$ \\
Fish farming & 340209 & $2.70 \%$ \\
\hline Total & 12591563 & $100.00 \%$ \\
\hline
\end{tabular}

Table 2. Preliminary survey results of Nile Delta and Nile valley during 2008/09 winter survey for major items

\begin{tabular}{|l|c|c|}
\hline \multicolumn{1}{|c|}{ Item } & $\begin{array}{c}\text { Area } \\
\text { (Feddan) }\end{array}$ & Percentages \\
\hline Wheat & 2547100 & $32.42 \%$ \\
Barley & 33100 & $0.42 \%$ \\
Suger beet & 197100 & $2.51 \%$ \\
Suger cane & 252600 & $3.21 \%$ \\
Beans & 302900 & $3.85 \%$ \\
Potato & 142400 & $1.81 \%$ \\
Tomato & 89300 & $1.14 \%$ \\
Other vegetables & 459100 & $5.84 \%$ \\
Berseem & 1926400 & $24.52 \%$ \\
Citrus & 446200 & $5.68 \%$ \\
Mango & 178100 & $2.27 \%$ \\
Other orchards & 488600 & $6.22 \%$ \\
Agricultural land without & 461700 & $5.88 \%$ \\
planted & & \\
Fish farming & 333100 & $4.24 \%$ \\
\hline Total & 7857700 & $100 \%$ \\
\hline
\end{tabular}




\section{REFERENCE}

Ali, R.R.; G.W. Ageeb and M.A. Wahab. (2007). Assessment of soil capability for agricultural use in some areas west of the nile delta, Egypt: an application study using spatial analyses. Journal of Applied Sciences Research, 3(11): 1622-1629.

Ayala-Silva, T.; G. Gordon and R. Heath. (2009). use of satellite data to study the impact of landcover/land-use change in madison county alabama. American Journal of Applied Sciences, 6(4): 656-660.

Gonzalez-Alonso, F. and J. M Cuevas. (1993). Remote sensing and agricultural statistics: crop area estimation through regression estimators and confusion matrices. International Journal of Remote Sensing, 14(6): 1215 -1219

Jensen, J.R. and D.J. Cowen. (1999). Remote sensing of urban/suburban infrastructure and socio-economic attributes. Photogrammetric Engineering and Remote Sensing, 65: 611-622. Lambin, E.F. and D. Elrlich. (1997). Land - cover changes in Sub- Saharan Africa (1982-1991): Application of a change index based on remotely sensed surface temperature and vegetation indices at a continental scale. Remote Sens. Environ, 61(2): 181-200.

Lenney, M.P.; C.E Woodcock,; J.B Collins and H Hamdi. (1996). The status of agricultural lands in Egypt: The use of Multi temporal NDVI features derived from landsat TM. Remote Sens. Environ, 56: 8-20.

Loveland, T.R.; T.L. Sohl; S.V. Stehman; A.L. Gallant; K.L. Sayler and D.E. Napton. (2002).
A strategy for estimating the rates of recent United States land-cover changes. Photogrammetric Engineering and Remote Sensing, 68: 10911099.

Pradhan, S. (2001). Crop Area Estimation using GIS, remote sensing and area frame sampling. International Journal of Applied Earth Observation and Geo-information, 3(1): 86 - 92.

Quarmby, N.A.; M. Milnes; T.L. Hindle and N. Silleos. (1993). The use of multi-temporal NDVI measurements from avhrr data for crop yield estimation and prediction. International Journal of Remote Sensing, 14(2): 199-210.

Rasmussen, M.S. (1997). Operational Yield Forecast using AVHRR NDVI data: Reduction of Environmental and Inter-annual variability. International Journal of Remote Sensing, 18(5): 10591077.

Rembold, F.; S. Carnicelli; M. Nori and A.G. Ferrari. (2000). Use of aerial photographs, Landsat TM imagery and multidisciplinary field survey for land -cover change analysis in the lakes region (Ethiopia). Int. J. Appli. Earth Observation and Geoinformation, 2(3-4):181- 189.

Rogana, J. and D. M. Chen. (2004). remote sensing technology for mapping and monitoring landcover and land-use change. Progress in Planning, 61: 301-325.

Youssef, A.M.; E.A. Zaghlou; M.F. Moussa and A.M. Mahdi, (2009). Litho logical mapping using land sat enhanced thematic mapper in the central eastern desert, Egypt: case study: area surround gabal al haded. Egypt. J. Remote Sensing and Space Sci., 12: 87-100. 